\title{
Correction to: Using an L7Ae-Tethered, Hydroxyl Radical-Mediated Footprinting Strategy to Identify and Validate Kink-Turns in RNAs
}

\section{Stella M. Lai and Venkat Gopalan}

Correction to:

Chapter 9 in: Robert J. Scarborough and Anne Gatignol (eds.), Ribozymes: Methods and Protocols, Methods in Molecular Biology, vol. 2167, https://doi.org/10.1007/978-1-0716-0716-9_9

Owing to an oversight, the words "Reverse" and "Cleaved" in Subheading 2.3.3 of Chapter 9 were spelt incorrectly in the book. These terms have been corrected.

The updated online version of this chapter can be found at:

https://doi.org/10.1007/978-1-0716-0716-9_9 